\title{
TRAJETÓRIA DE CONSTRUÇÃO DOS DIREITOS IMANENTES A CIDADANIA SOCIAL BRASILEIRA
}

\author{
Huama Maximo $^{1}$ \\ Elizete Conceição Silva ${ }^{2}$
}

\begin{abstract}
RESUMO: O artigo apresenta uma reflexão referente a trajetória de construção dos direitos imanentes à cidadania social brasileira em uma perspectiva histórica crítica. Por meio de dados bibliográficos objetivou-se analisar a trajetória de construção dos elementos inalienáveis à cidadania social, os quais: o direito social, o direto político e o direito civil. No decorrer do século XX, os diversos movimentos sociais organizados da sociedade, partidos políticos, sindicatos e organizações não governamentais, entre outras, lutaram pela obtenção da cidadania social, a qual foi alcançada com a promulgação da Constituição Federal de 1988. No entanto, após três décadas da promulgação da constituição, a desigualdade social ainda se faz presente. Em virtude de falta de conhecimento dos elementos inerentes, nem todos os cidadãos usufruem da cidadania social plena.
\end{abstract}

Palavras-chave: Mobilização social; Cidadania social; Status social.

\section{TRAJECTORY OF CONSTRUCTION OF THE RIGHTS IMMANENT TO BRAZILIAN SOCIAL CITIZENSHIP}

\begin{abstract}
The article presents a reflection regarding the trajectory of construction of the rights immanent to Brazilian social citizenship in a critical historical perspective. Through bibliographic data, the objective was to analyze the trajectory of construction of the elements that are inalienable to social citizenship, which are: the social right, the political right and the civil right. During the 20th century, the various organized social movements of society, political parties, unions and nom-governmental organizations, among others, fought for obtaining the social citizenship, which was achieved with the promulgation of the Federal Constitution of 1988. However, three decades after the promulgation of the constitution, the social inequality is still present. Due to lack of knowledge of the inherent elements, not all citizens enjoy full social citizenship.
\end{abstract}

Keywords: Social mobilization; Social citizenship; Social status.

\section{INTRODUÇÃO}

\footnotetext{
${ }^{1}$ Mestranda em Ciências Sociais pela Universidade Estadual de Maringá, UEM, Maringá, Brasil. E-mail: huamamaximo@gmail.com

${ }^{2}$ Docente adjunto do departamento de Ciências Sociais, da Universidade Estadual de Maringá, UEM, Maringá, Câmpus Regional Vale do Ivaí, CRV, PR, Brasil. E-mail: elizetecsilva2007@gmail.com

Programas de Pós-Graduação em Ciências Sociais e Filosofia - UNIOESTE - Rua da Faculdade 645. Toledo - PR. CEP 85.903-000 Email: revistaalamedas@gmail.com
} 
O presente artigo $^{3}$ objetiva analisar a trajetória de construção dos direitos imanentes à cidadania social brasileira e abordar a origem e o desenvolvimento da luta da classe trabalhadora brasileira em busca da conquista da cidadania social no limiar do século XX.

Para a elaboração do artigo foi realizado o levantamento bibliográfico de livros, artigos, revistas científicas, dentre outros, para o aprofundamento teórico sobre a temática.

A cidadania social é uma reunião dos direitos e deveres que definem a condição legal de um ser humano perante a sociedade. A história de reivindicações e lutas sociais vai estabelecer a trajetória do desenvolvimento dos direitos inalienáveis e inerentes à cidadania social nas nações em geral. No entanto, o processo de construção da cidadania social, no tocante a conquista dos elementos intrínsecos que a compõem, ou seja, o direito civil, o direito político e o direito social apresentaram diferenças, tanto no modo, quanto no momento histórico nas diferentes nações.

$\mathrm{O}$ direito social, elemento intrínseco e inerente à cidadania social, foi implantado no Brasil na era Vargas (1930-1945), por meio de regulamentações tais como: a Consolidação das Leis de Trabalho - CLT, os direitos previdenciários e os sindicais. Os conjuntos de medidas legais abrangeram os trabalhadores regulamentados ao mercado formal de trabalho, permanecendo excluídas algumas categorias de trabalhadores, tais como os rurais. [...] A cidadania que daí resultava era passiva e receptora antes que ativa e reivindicadora (CARVALHO, 2003, p. 26).

Na década de 1980, com o quadro de recessão econômica agravou-se a desigualdade social. Neste contexto, os movimentos organizados da sociedade intensificaram as lutas sociais em busca de direitos, principalmente os direitos sociais, em consequência, após alguns anos, findou-se o Regime Militar (1964-1985) no país. Os movimentos sociais de diversos segmentos apresentavam e representavam as demandas sociais da sociedade, sendo que algumas das propostas foram promulgadas na Constituição Federal em 1988. A preocupação com a construção dos direitos civis, políticos e sociais, fez com que a Carta Magna, ficasse conhecida como a Constituição

\footnotetext{
${ }^{3}$ Consiste em um recorte da pesquisa de iniciação científica, patrocinada pelo Conselho Nacional de Desenvolvimento Científico e Tecnológico - CNPQ. 
Cidadã, “[...] um longo e minucioso documento em que a garantia dos direitos do cidadão era a preocupação central" (CARVALHO, 2003, p. 200).

Se por um lado foram assegurados avanços referentes à conquista da cidadania social brasileira, por meio da promulgação do texto Constitucional, por outro lado, a desigualdade social existente desde a colonização do país persistiu e avançou na contemporaneidade.

\section{ELEMENTOS IMANENTES A CIDADANIA SOCIAL}

Ao resgatar a discussão sobre o conceito de cidadania realizada por Marshall (1967), cumpre destacar que, para o referido autor conceituar cidadania significa necessariamente refletir seus elementos intrínsecos, são eles: o direito civil, o direito político e o direito social. Na ausência de qualquer um desses direitos do cidadão inexiste a cidadania social plena. Em uma nação, em que seja nulo qualquer um dos elementos acima referidos, inalienáveis do ser social, o cidadão estará à margem da cidadania social. Para Marshall é a história da constituição do direito civil que possibilita a sua análise.

[...] Mas a análise é, neste caso, ditada mais pela história do que pela lógica. O elemento civil é composto dos direitos necessários à liberdade individual liberdade de ir e vir, liberdade de imprensa, pensamento e fé, o direito à propriedade e de concluir contratos válidos e o direito à justiça. Êste último difere dos outros porque é o direito de defender e afirmar todos os direitos em termos de igualdade com os outros e pelo devido encaminhamento processual. Isto nos mostra que as instituições mais ìntimamente associadas com os direitos civis são os tribunais de justiça [...] (MARSHALL, 1967, p. 63-64).

Quanto ao elemento político, Marshall (1967) considera que este assegura o exercício ao direito político de votar e ser votado:

[...] Por elemento político se deve entender o direito de participar no exercício do poder político, como um membro de um organismo investido da autoridade política ou como um eleitor dos membros de tal organismo. As instituições correspondentes são o parlamento e conselhos do Govêrno local [...] (MARSHALL, 1967, p. 64). 
Ainda, para o referido autor, o elemento social proporciona aos indivíduos o acesso ao direito social.

[...] O elemento social se refere a tudo o que vai desde o direito a um mínimo de bem-estar econômico e segurança ao direito de participar, por completo, na herança social e levar a vida de um ser civilizado de acôrdo com os padrões que prevalecem na sociedade. As instituições mais ìntimamente ligadas com êle são o sistema educacional e os serviços sociais (MARSHALL, 1967, p. 64).

Em suas reflexões sobre o conceito de cidadania, Marshall (1967) observa que a história de reivindicações e lutas sociais estabelece, em cada nação, a trajetória do desenvolvimento dos direitos inalienáveis à cidadania social. Visto que a emergência de cada um dos elementos que compõem a cidadania social não tem uma ordem cronológica específica para o seu aparecimento. O autor conceitua cidadania como:

[...] A cidadania é um status concedido àqueles que são membros integrais de uma comunidade. Todos aquêles que possuem o status são iguais com respeito aos direitos e obrigações pertinentes aos status. Não há nenhum princípio universal que determine o que estes direitos e obrigações serão, mas as sociedades nas quais a cidadania é uma instituição em desenvolvimento criam uma imagem de uma cidadania ideal em relação à qual o sucesso pode ser medido e em relação à qual a aspiração pode ser dirigida [...] (MARSHALL, 1967, p. 76).

Para Marshall (1967), o status de cidadania desenvolveu-se paralelamente com o sistema capitalista. Na Inglaterra, este status de cidadania surgiu em meados do século XVII e ocorreu com a introdução dos direitos civis no século XVIII, a dos direitos políticos no século XIX e os direitos sociais no século XX. A cidadania tem por pressuposto possibilitar a todos, indistintamente, direitos e deveres legais em dada sociedade.

\section{SINGULARIDADES DA TRAJETÓRIA DE CONSTRUÇÃO DA CIDADANIA SOCIAL BRASILEIRA}

De acordo com Carvalho (2003), a construção da cidadania social na nação brasileira ocorreu no século XX, com o avanço de um dos elementos intrínsecos e inerentes à cidadania: o direito social. 
O ano de 1930 foi o divisor de águas na história do país. A partir dessa data, houve aceleração das mudanças sociais e políticas, a história começou a andar mais rápido. No campo que aqui nos interessa, a mudança mais espetacular verificou-se no avanço dos direitos sociais [...] (CARVALHO, 2003, p. 87).

Segundo o autor, no final da Primeira República (1889-1930) e, no início do governo Revolucionário (1930-1934), iniciou-se o processo de implantação e regulamentação da legislação trabalhista e previdenciária inexistente até então, que alcançou seu auge em 1943, com a Consolidação das Leis de Trabalho (CLT). Porém, esta não abarcou a todas as categorias de trabalhadores, ficando de fora os trabalhadores rurais essenciais à macroeconomia na época. Esse processo de regulamentação do trabalho urbano iniciou com a criação do Ministério do Trabalho, Indústria e Comércio em 1930, com o intuito de evitar divergências entre empregadores e empregados, e legitimar o governo revolucionário, viabilizando o programa de governo que se voltava ao desenvolvimento da industrialização no país.

No Brasil, ainda de acordo com Carvalho (2003), o primeiro passo à conquista do direito social ocorreu com a regulamentação do direito trabalhista, previdenciário e sindical, porém, devido a ser voltada apenas aos trabalhadores urbanos de alguns setores estratégicos ao desenvolvimento da economia nacional, só foram beneficiados os trabalhadores inseridos no trabalho formal. Este é o motivo de o autor considerar que o início do processo à cidadania tenha sido seletivo.

Para Santos (1997), a legislação trabalhista que existiu na era Vargas (19301945), priorizou algumas categorias de profissionais em detrimento de outras que permaneceram desprotegidas.

São cidadãos todos aqueles membros da comunidade que se encontram localizados em qualquer uma das ocupações reconhecidas e definidas em lei. [...] A cidadania está embutida na profissão e os direitos do cidadão restringem-se aos direitos do lugar que ocupa no processo produtivo, tal como reconhecido por lei. Tornam-se pré-cidadão, assim todos aqueles, cuja ocupação a lei desconhece (SANTOS, 1997, p. 68 apud MORAIS, 2011, p.19) $)^{4}$

\footnotetext{
${ }^{4}$ A referida citação encontra-se na obra intitulada: Cidadania e justiça: a política social na ordem política brasileira de autoria de Wanderley Guilherme Santos em 1997, sendo citada em artigo científico publicado no Programa de Pós-Graduação em História da Universidade de Brasília PPG-HIS em 2011 de 
Naquele momento foram considerados cidadãos somente os trabalhadores urbanos empregados em setores estratégicos e indispensáveis ao desenvolvimento industrial. Os trabalhadores das demais categorias, que não foram contemplados na legislação, não foram reconhecidos como cidadãos, mas sim, pré-cidadão, como por exemplo: os trabalhadores rurais (SANTOS, 1997, p. 68 apud MORAIS, 2011, p. 19).

Importantes categorias de trabalhadores foram deixadas desprotegidas com a construção dos direitos sociais trabalhistas, previdenciário e sindical no início do século XX.

[...] Ficavam ainda de fora todos os trabalhadores rurais, que na época ainda eram maioria. Tratava-se, portanto, de uma concepção da política social como privilégio e não como direito. Se fosse concedida como direito, deveria beneficiar a todos e da mesma maneira. Do modo como foram introduzidos, os benefícios atingiam aqueles a quem o governo decidia favorecer, de modo particular aqueles que se enquadravam na estrutura sindical corporativa montada pelo Estado. Por esta razão, a política social foi bem caracterizada por Wanderley G. dos Santos como 'cidadania regulada', isto é, uma cidadania limitada por restrições políticas (CARVALHO, 2003, p. 114-115).

Se na era Vargas o direito à sindicalização e a implantação e regulamentação das relações trabalhistas não adentraram ao território de domínio dos latifundiários, na década de 1960, em decorrência da importância do setor agrário, sobreveio o direito à sindicalização aos trabalhadores rurais, por meio da lei que garantia o direito a rede de proteção à categoria de trabalhadores rurais.

De acordo com Carvalho (2003), o direito social conquistado foi compreendido pela maioria da população como caridade e, também, fomentou o sentimento de gratidão.

[...] Mas, em contrapartida, colocava os cidadãos em posição de dependência perante os lideres, aos quais votavam lealdade pessoal pelos benefícios que eles de fato ou supostamente lhes tinham distribuído. A antecipação dos direitos sociais fazia com que os direitos não fossem vistos como tais, como independentes da ação do governo, mas como um favor em troca do qual se deviam gratidão e lealdade. A cidadania que daí resultava era passiva e receptora antes que ativa e reivindicadora (CARVALHO, 2003, p. 126).

autoria de Michelle Nunes de Moraes com o título: Trabalhadores Rurais e Cidadania no Brasil - 19301964.

Programas de Pós-Graduação em Ciências Sociais e Filosofia - UNIOESTE - Rua da 
Conforme o autor, devido ao fato do direito social ter sido implantado e regulamentado no período ditatorial, em muitos casos ele foi considerado como benesse do governo pela população, ou seja, um favor e não um direito.

Quanto à conquista e obtenção do direito político, outro elemento essencial que compõe a cidadania social, este iniciou sua caminhada no primeiro período da era Vargas (1930 à 1937).

Carvalho (2003) considera que o fato da Revolução Constitucionalista, ocorrida no ano de 1932, ter exigido tanto a convocação de uma Constituinte quanto a elaboração de um código eleitoral para assegurar eleições limpas no país, a mesma pode ser considerada o marco do direito político. Ressalta-se que após três meses de confronto com o Estado de São Paulo, o governo de Getúlio Vargas cedeu às exigências e, em 1933 ocorreram as eleições.

[...] Para reduzir as fraudes, foi introduzido o voto secreto e criada uma justiça eleitoral. $\mathrm{O}$ voto secreto protegia o eleitor das pressões dos caciques políticos; a justiça eleitoral colocava nas mãos de juízes profissionais a fiscalização do alistamento, da votação, da apuração dos votos e o reconhecimento dos eleitos. O voto secreto e a justiça eleitoral foram conquistas democráticas. Houve também avanços na cidadania política. Pela primeira vez as mulheres ganharam o direito ao voto (CARVALHO, 2003, p. 101).

As eleições representaram um avanço político rumo à cidadania social, ao possibilitar o acesso das mulheres ao direito de voto, entretanto, os indivíduos analfabetos permaneceram excluídos do referido direito. $\mathrm{O}$ voto secreto foi uma tentativa de dificultar às oligarquias políticas a manipulação dos resultados eleitorais. Anteriormente, os latifundiários induziam a fraude eleitoral, os eleitores votavam de acordo com os interesses das oligarquias políticas, que ocorria por meio do voto de cabresto ${ }^{5}$.

No Brasil, tanto os direitos políticos, quanto os direitos civis vieram com a Constituição Federal de 1946.

\footnotetext{
${ }^{5}$ De acordo com Carvalho 2003, na Primeira República (1889-1930), as oligarquias políticas utilizavam seu poder e influência, para induzir a população a votarem conforme os interesses dos fazendeiros em seus redutos políticos, por meio do denominado voto de cabresto. Tal denominação refere-se a compra de votos ou o uso do poder econômico como forma de coação do eleitor, em outras palavras, os indivíduos votam de acordo com os interesses do mandatário. Prática recorrente no coronelismo.
} 
A Constituição de 1946 manteve as conquistas sociais do período anterior e garantiu os tradicionais direitos civis e políticos. Até 1964, houve liberdade de imprensa e de organização política. Apesar de tentativas de golpes militares, houve eleições regulares para presidente da República, senadores, deputados federais, governadores, deputados estaduais, prefeitos e vereadores [...] (CARVALHO, 2003, p. 127).

Como afirma Carvalho (2003), a Constituição de 1946, garantiu a população brasileira o direito de votar e ser votado nos níveis: municipal, estadual e federal, exceto aos analfabetos. Ainda assegurou os direitos civis e a liberdade de imprensa e conservou as conquistas sociais. Nesse período havia somente uma barreira, a proibição do direito de greve aos trabalhadores, porém, esta não foi um empecilho, pois aconteceram diversas manifestações durante os anos de 1946 a 1964.

Conforme Carvalho (2003), o golpe civil-militar de 1964, rebateu severamente sobre os direitos de cidadania social, principalmente os civis e os políticos que foram cerceados de maneira mais intensa, durante a segunda era Vargas (1937-1945). Quanto aos direitos sociais, principalmente os relacionados ao mundo rural, estes foram ampliados, o que propiciou aos trabalhadores rurais arrimo de família o acesso ao direito previdenciário, porém, manteve-se a disparidade entre o direito previdenciário do trabalhador rural e do trabalhador urbano. A ampliação dos direitos sociais ocorreu com o pressuposto de legitimar o Regime Autocrático, ou seja, manter o regime militar no comando da nação.

A partir de 1974, com o colapso do milagre econômico, que exacerbou o quadro de desemprego estrutural, agravando ainda mais a desigualdade social surgem os movimentos de mobilização e organização popular, os quais foram de suma importância para o findar do Regime Militar.

[...] A ampliação dos mercados de consumo e de emprego e o grande crescimento das cidades durante o período militar criaram condições para a ampla mobilização e organização social que aconteceram após 1974. O movimento pelas eleições diretas em 1984 foi o ponto culminante de um movimento de mobilização política de dimensões inéditas na história do país (CARVALHO, 2003, p. 192-193).

O crescimento desordenado das grandes metrópoles, em decorrência do fluxo contínuo de êxodo rural, contribuiu para o cenário de mobilização e organização social 
em busca de direitos inerentes à cidadania social, principalmente o direito político de votar e ser votado, bem como, da realização de eleições diretas para presidente da república no ano de 1984, a qual veio a ser concretizada após cinco anos e, a quase três décadas do golpe civil-militar.

O processo de redemocratização do país, contou com ampla mobilização da população em geral, bem como, de diversos movimentos sociais reivindicatórios e de inúmeros segmentos da sociedade brasileira, que participaram ativamente na Assembleia Nacional Constituinte - $\mathrm{ANC}^{6}$ de 1987, por meio de diferentes propostas.

Com o esgotamento da Autocracia Burguesa, provocado pelo enfraquecimento do Regime Militar (1964-1985) e o afastamento de parte das classes sociais que apoiaram o golpe civil-militar em 1964; com o fim do milagre econômico; aumento do desemprego estrutural e a crescente dívida externa contraída pelo Estado, dentre outros fatores, o processo de redemocratização do país apresentou uma transição lenta, até chegar ao marco legal, com a promulgação da Constituição Federal em 1988 (ROJAS COUTO, 2010).

\begin{abstract}
No curso do esgotamento dos governos militares, foi enunciada e promulgada a Constituição de 1988, produto de um processo de disputas democráticas com participação popular, que gestou um texto constitucional ambíguo, extremamente avançado do ponto de vista conceitual, mas restritivo do ponto de vista da ordem econômica, que manteve os princípios já enunciados nos outros textos constitucionais. $\mathrm{O}$ avanço central no texto constitucional está alicerçado no deslocamento do campo particular para a universalização dos direitos, não mais centrados nos méritos, mas nas necessidades sociais (ROJAS COUTO, 2010, p.186).
\end{abstract}

Para a autora, a Constituição Federal de 1988 foi elaborada por meio de amplo debate na sociedade brasileira, com a participação de diversos movimentos sociais que apresentavam e, representavam as demandas sociais, partidos políticos, sindicatos, organizações não governamentais entre outras. $\mathrm{O}$ foco central do texto constitucional se situava no campo da universalização dos direitos políticos, econômicos e sociais, sem distinção. Por esse motivo, a Constituição Federal de 1988 ficou conhecida como a

\footnotetext{
${ }^{6}$ No período referente de primeiro de fevereiro de 1987 ao mês de outubro de 1988, a Assembleia Nacional Constituinte (ANC), que era formada por representantes partidários, como os deputados federais e os senadores da República. A (ANC) era constituída por comissões que debatiam diversas temáticas, como na área de previdência social (CARVALHO, 2003). 
Constituição Cidadã, sendo promulgada com 40 anos de atraso, se comparado a outros países como a Europa e os Estados Unidos.

Silva (2012) ressalta que a sociedade brasileira foi incentivada a participar, por meio da Assembleia Nacional Constituinte da construção da Constituição Federal de 1988:

[...] o incentivo à participação popular 'fez com que 122 movimentos populares enviassem emendas à $\mathrm{ANC}$, assinadas por mais de 12 milhões de eleitores, e 83 foram defendidas na ANC'. Ademais, 72.719 sugestões foram aportadas no Congresso Nacional por intermédio dos correios (SILVA, 2012, p. 134).

De acordo com a autora, a Assembleia Nacional Constituinte (ANC), durante o processo de construção da Constituição Federal de 1988, tinha contato direto com os cidadãos e recebia diversas propostas da sociedade civil, seja por meio dos movimentos sociais que a representava, ou da participação dos cidadãos que endereçavam suas propostas por meio da rede de comunicação estatal, os correios. Algumas das propostas enviadas à Assembleia Nacional Constituinte (ANC) foram aceitas e incluídas pelos Constituintes, como por exemplo: o sistema de proteção social. Ainda, para a mesma autora, os movimentos sociais levantaram a bandeira da vitória, com a conquista do sistema de proteção social que foi promulgado na Carta Magna em 1988.

[...] O nascimento da seguridade social, além de uma conquista significativa dos movimentos organizados da sociedade, impôs uma nova lógica para presidir a proteção social no país, a lógica da universalização do acesso aos direitos relativos à saúde, à previdência social e à assistência social. Uma lógica que estava na contramão do que vinha ocorrendo nos países do capitalismo avançado, em que a reestruturação produtiva, associada ao redimensionamento das funções do Estado e à financeirização do capital, impunha um desmantelamento dos sistemas de proteção social, mercantilizando fortemente essa proteção [...] (SILVA, 2012, p. 273-274).

A promulgação da Constituição Federal brasileira em 1988 aconteceu em um período histórico no qual o Estado, em países de capitalismo avançado, estava transferindo parte de suas responsabilidades e atribuições sociais para o mercado. Este passava a buscar lucratividade e realizar a mercantilização de setores que, até então, eram de responsabilidade do Estado, tais como: a saúde, a educação e a previdência social, entre outros. Nesse mesmo período, o Brasil enfrentava uma crise econômica 
com o aumento da inflação e elevado índice de desemprego estrutural, o que agravou o quadro de recessão e a diminuição da atividade econômica.

Em meio a uma conjuntura adversa surgiu o sistema de proteção social brasileiro com o pressuposto de universalização ao direito de acesso à política de saúde a todos os cidadãos e, um sistema de seguro social contributivo que propiciava aos trabalhadores, que contribuíssem com a previdência social, o acesso aos benefícios sociais previdenciários de cobertura na velhice, bem como em virtude de doenças, entre outros, e o direito ao acesso à política de assistência social aos indivíduos em situação de vulnerabilidade social (SILVA, 2012).

Como indica Carvalho (2003), dentre os elementos intrínsecos à cidadania social, o elemento que apresenta desconhecimento pela sociedade brasileira, é o direito civil, devido ao fato de a maioria dos cidadãos desconhecerem a dimensão dele.

\footnotetext{
[...] No entanto, pode-se dizer que, dos direitos que compõe a cidadania, no Brasil são ainda os civis que apresentam as maiores deficiências em termos de seu conhecimento, extensão e garantias. A precariedade do conhecimento dos direitos civis, e também dos políticos e sociais, é demonstrada por pesquisa feita na região metropolitana do Rio de Janeiro em 1997. A pesquisa mostrou que $57 \%$ dos pesquisados não sabiam mencionar um só direito e só $12 \%$ mencionaram algum direito civil. Quase a metade achava que era legal a prisão por simples suspeita. A pesquisa mostrou que o fator mais importante no que se refere ao conhecimento dos direitos é a educação [...] (CARVALHO, 2003, p. 210).
}

Segundo Carvalho (2003), os direitos civis historicamente cerceados na sociedade brasileira, especialmente na era Vargas e no período do Regime Militar e, estabelecidos na Carta Magna, a grande maioria da população não os usufrui em sua plenitude. " [...] Os dados revelam ainda que educação é o fator que mais bem explica o comportamento das pessoas no que se refere ao exercício dos direitos civis e políticos. Os mais educados se filiam mais a sindicatos, a órgãos de classe, a partidos políticos" (p. 210). O baixo nível de instrução, que abrange um número expressivo de brasileiros, representa um empecilho ao gozo pleno dos direitos civis e políticos, bem como, sociais. Se por um lado, a sociedade brasileira conquistou no limiar do século XX os elementos inerentes a cidadania plena, por outro lado, há um significativo número de cidadãos que desconhecem os direitos arduamente conquistados. 
Se por um lado, os avanços obtidos na esfera dos direitos sociais ampliaram com a promulgação da Constituição Federal de 1988, mais que qualquer outra Constituição Federal anterior, por outro lado, a desigualdade social que surgiu com o início da colonização do Brasil em 1500, persistiu e avançou no decorrer da história da nação.

\begin{abstract}
A escandalosa desigualdade que concentra nas mãos de poucos a riqueza nacional tem como conseqüência níveis dolorosos de pobreza e miséria. Tomando-se a renda de 70 dólares - que a Organização Mundial da Saúde (OMS) considera ser o mínimo necessário para a sobrevivência - como a linha divisória da pobreza, o Brasil tinha em 1997, 54\% de pobres. A porcentagem correspondia a 85 milhões de pessoas, numa população total de 160 milhões. No Nordeste, a porcentagem subia para 80\%. A persistência da desigualdade é apenas em parte explicada pelo baixo crescimento econômico do país nos últimos 20 anos. Mesmo durante o período de alto crescimento da década de 70 ela não se reduziu. Crescendo ou não, o país permanece desigual. $\mathrm{O}$ efeito positivo sobre a distribuição de renda trazida pelo fim da inflação alta teve efeito passageiro. A crise cambial de 1999 e a consequente redução do índice de crescimento econômico eliminaram as vantagens conseguidas no início (CARVALHO, 2003, p. 208-209).
\end{abstract}

A denominada Constituição Cidadã, mesmo ao priorizar os direitos sociais, os quais avançaram com a implementação da seguridade social (composta do tripé: previdência social, saúde e assistência social), bem como, promulgar os demais elementos inerentes à Cidadania Social, sejam eles: o direito civil e politico, não conseguiu extinguir com a desigualdade social que persiste em permanecer na história brasileira.

Ao falar em desigualdade social, reporta-se ao pensamento de Marx (1965), que a considera como decorrente da estratificação social, ou seja, em consequência da relação contraditória entre os detentores dos meios de produção e os possuidores da força de trabalho. Deste modo, a distribuição da riqueza social ocorre de maneira desigual e consequentemente a desigualdade apresenta nos mais variados âmbitos, ou seja: econômico, político, social e cultural.

Por considerar a abrangência do conceito de "desigualdade social" a discussão no tocante a desigualdade social e, reportando-se ao pensamento de Marx (1965), optase por refletir sobre a desigualdade social e econômica, relacionada aos fatores: renda e cultura. 
A desproporcionalidade na distribuição de renda pode ser visualizada no campo laboral. A remuneração dos trabalhadores sofre variação a depender da função desempenhada e da qualificação necessária para realiza-la. Como tal qualificação relaciona-se ao conhecimento, experiência e habilidades que atendam a demanda do mercado de trabalho. Apenas uma minoria de trabalhadores tem condições de manter-se qualificado ininterruptamente, a grande maioria não consegue qualificar-se e, caso consiga, dificilmente consegue manter atualizado seus atributos, enfim, em uma sociedade na qual tudo se torna mercadoria, até mesmo o ser humano (trabalhador) e, frente ao mundo de trabalho que a cada dia se dinamiza com mais rapidez, a mão de obra desqualificada para atender ao atual mercado laboral, vivencia cotidianamente a desigualdade social (CARVALHO, 2003).

Carvalho (2003) considera que a instrução é essencial para os trabalhadores em geral, visto que ela propicia a qualificação profissional e, consequentemente uma melhor condição de vida. No entanto, nem todos conseguem obter tal qualificação, devido a fatores como: o início precoce ao exercício do trabalho, ausência de recursos financeiros, entre outros.

$\mathrm{Na}$ esfera social ressalta-se o fator educação, esta fundamental para que a população possa usufruir dos elementos inerentes a cidadania social e, participar social e politicamente na sociedade, bem como, conhecer e acessar seus direitos. Ressalta-se que o direito civil é o de menor conhecimento da população tanto em sua extensão, quanto em suas garantias (CARVALHO, 2003).

Com essa breve reflexão a respeito do conceito desigualdade social, pode-se constatar, que o fator renda e cultura encontram-se imbricados, bem como, que no Brasil, ambos tornam-se empecilhos para o alcance da plena cidadania social.

\section{CONCLUSÃO}

Em cada Estado nacional a conquista dos elementos intrínsecos e inerentes à cidadania social ocorreu em ordem cronológica distinta. Em território brasileiro a trajetória de construção da cidadania social mostrou-se lenta, e se conquistou o primeiro elemento que a compõem o direito social, no período da era Vargas (1930 - 1945). Os demais elementos, o direito civil e o direito político somente foram alcançados, com o 
findar da Autocracia Burguesa (1964 -1985), ou seja, posterior ao ano de 1984, por meio da promulgação da Constituição Federal de 1988.

O direito social, o primeiro elemento da cidadania social se conquistou, em razão das reivindicações e lutas sociais da classe trabalhadora. $\mathrm{O}$ referido direito regulamentou as leis trabalhistas, previdenciárias e sindicais, porém, apresentou um caráter seletivo, devido ter contemplado trabalhadores inseridos ao mercado formal de trabalho, as demais trabalhadores permaneceram desprotegidas.

No decorrer dos anos o direito social alcançou a totalidade da população, mas não igualitariamente a todos os trabalhadores, bem como, os direitos políticos e civis igualmente apresentaram uma morosidade. Se por meio da promulgação da Constituição Federal de 1946, os direitos civis e políticos foram contemplados de modo que as mulheres passaram a terem o direito a voto, os analfabetos permaneceram excluídos a tal direito.

Se para os brasileiros, a conquista da cidadania ocorria lentamente, com o golpe civil-militar de 1964, os elementos inerentes à cidadania social foram abruptamente interrompidos, por mais de duas décadas (1964-1985), quando em resposta a uma relevante mobilização da sociedade civil, houve a promulgação da Constituição Federal de 1988, a qual veio assegurar universalmente os direitos: civil, social e político, ou seja, os elementos intrínsecos da cidadania social passaram a ser direito de todos, independentes de cor, raça, credo, sexo, etc.

No entanto, no Brasil, o que se constata após três décadas da conquista da cidadania social, é que logo após sua conquista, as investidas de desconstrução, se fizeram e fazem presentes, além de que, mesmo com sua conquista, a desigualdade social continua presente no território brasileiro.

Frente a este contexto histórico, pode-se afirmar que a cidadania social plena no Brasil, não foi alcançada e, possui ainda um longo trajeto a percorrer. Constata-se que o maior obstáculo para sua obtenção é a desigualdade social instaurada desde a colonização do país e que persiste na contemporaneidade como empecilho que deve ser vencido. Por fim, considera-se que, no território brasileiro, a cidadania em sua plenitude será alcançada, com o findar ou ao menos, com a redução drástica da desigualdade social. 


\section{REFERÊNCIAS BIBLIOGRÁFICAS}

CARVAlHO, J. M. CIDADANIA NO BRASIL: O Longo Caminho. 4. ed. Rio de Janeiro: editora Civilização Brasileira, 2003.

MARSHALL T. H. CIDADANIA, CLASSE SOCIAL E STATUS. Rio de Janeiro: editora ZAHAR EDITORES, 1967.

MARX, K. Avant-Propos. Critique de I'Économie Politique (1859). In: Marx, Karl. (Euvres. Trad: Maximilien Rubel. Paris: Gallimard, 1965. V. I: Èconomie.

MORAES, Michelle Nunes de. Trabalhadores Rurais e Cidadania no Brasil - 19301964. Em Tempo de Histórias - Publicação do Programa de Pós-Graduação em História da Universidade de Brasília PPG-HIS, n. ${ }^{\circ}$ 19, Brasília: ago/dez. 2011. ISSN 1517-1108. p. 16-34.

ROJAS COUTO, Berenice. O Direito Social e a Assistência Social na Sociedade Brasileira: uma equação possível?. 4. ed. São Paulo: editora Cortez, 2010.

SANTOS, Wanderley Guilherme. Cidadania e justiça: a política social na ordem política brasileira. Rio de Janeiro: Campus, 1997.

SILVA, Maria Lucia Lopes da. PREVIDÊNCIA SOCIAL NO BRASIL: (dês)estruturação do trabalho e condições para sua universalização. São Paulo: Editora Cortez, 2012. 